\title{
Teaching Medical Students About Attention Deficit Hyperactivity Disorder (ADHD): The Design And Development Of An E-Learning Resource
}

This article was published in the following Dove Press journal:

Advances in Medical Education and Practice

\section{Gill Salmon' \\ Michal Tombs $\mathbb{D}^{2}$ \\ Katy Surman $\mathbb{D}^{3}$}

'Neurodevelopmental Disorders Team, Neath Port Talbot Hospital, Port Talbot SAI2 7BX, UK; ${ }^{2}$ C4ME, School of Medicine, Cardiff University, Cardiff CFI4 4YS, UK; ${ }^{3}$ Medical Student, University of Cambridge, School of Clinical Medicine, Addenbrookes Hospital, Cambridge CB2 OSP, UK
Correspondence: Michal Tombs C4ME, School of Medicine, Cardiff University, Neuadd Meirionnydd, Heath Park, Cardiff CFI4 4YS, UK Tel +44292068743 I

Email TombsM2@cardiff.ac.uk

\begin{abstract}
In this paper, we describe how an e-learning resource on Attention Deficit Hyperactivity Disorder (ADHD) for medical students was designed and developed. The aim of the resource was to provide students with essential knowledge and understanding about ADHD prior to their attendance at a classroom teaching session as well as to serve as a revision tool. The paper focuses on the way in which instructional design, educational and multimedia principles were used to inform the development of the resource. It also reports results of a small-scale evaluation of students' satisfaction with the resource and the way in which they believed it impacted knowledge acquisition of ADHD related concepts and principles. In addition, we consider ways in which the resource could be further utilized and evaluated, for example as part of a flipped classroom approach to learning, and whether this would be a useful model to use when teaching other aspects of Child and Adolescent Psychiatry.
\end{abstract}

Keywords: ADHD, ADDIE, PACT analysis, instructional design, multimedia principles, flipped classroom

\section{Introduction}

The increased complexity of medicine requires medical schools to review and revise the undergraduate medical curriculum, often resulting in addition of new topics. ${ }^{1}$ However, the time available for teaching is limited and educators may struggle to cover important topics within an increasingly constrained timeframe. ${ }^{2}$ In an attempt to address this issue, educators have looked for teaching techniques that will help them maximize the use of teaching time to ensure the ever-expanding curriculum is covered. E-learning resources are being increasingly used as teaching aids in medical education. Such resources have many advantages for medical students such as enabling them to engage in independent and individualised learning, ${ }^{3,4}$ as well as offering students the flexibility to study at a time that suits them and at their own pace. ${ }^{5}$ High rates of student satisfaction with e-learning have been reported, with many finding it an effective way of learning. ${ }^{6,7}$ It is interesting to note however, that many medical students do not anticipate e-learning completely replacing traditional teaching methods, ${ }^{8}$ viewing it more as a tool to complement them in a "blended" or "flipped classroom" approach. 9 Moreover, e-learning has been shown to be at least as effective as traditional lecturing in many medical disciplines, and across many stages of medical education. ${ }^{4,5,10}$

The importance of using well established and robust educational principles when designing e-learning resources has been discussed extensively in the literature. ${ }^{7}$ 
However, newcomers into this area may find it difficult to decide which theory or framework to use. This paper adds to the current literature on e-learning and the teaching of undergraduate Child and Adolescent psychiatry (CAP) by describing how instructional design, educational, and multimedia principles were used in grounding the design and development of an e-learning resource (https://xerte.cardiff.ac.uk/ play.php?template $\mathrm{id}=1501$ ) to teach the principles of ADHD to medical students. It also reports preliminary evaluation by considering students' satisfaction and the impact of the online resource on their knowledge of ADHD. Consideration is given to how the resource could be evaluated more extensively and rigorously in order to identify its educational value and impact on knowledge and skill acquisition.

\section{Background}

The amount of time devoted to teaching CAP to undergraduate medical students in medical schools across the world is, on average, small and there is limited agreement about appropriate curriculum content. ${ }^{11}$ Given the increase in prevalence in Child and Adolescent mental health problems, calls have been made to increase the amount of teaching of associated topics and to prioritise teaching CAP clinical skills over CAP knowledge. ${ }^{12-14}$ For example, in a recent Delphi study of undergraduate curriculum content in CAP, participants gave a high priority to application of knowledge and to clinical skills such as interviewing parents and taking a child and adolescent psychiatric history. ${ }^{15}$ In an attempt to help educators maximize the use of available CAP teaching time, an e-learning resource for medical students on ADHD was developed as it was thought this might be a useful adjunct to classroom approaches to teaching ADHD knowledge or related clinical skills.

\section{Overview Of Design And Development Principles}

The design and development of the ADHD e-learning resource were based upon a range of instructional design, educational and multimedia principles. A literature search revealed the ADDIE model (Analysis; Design; Development; Implementation and Evaluation) for designing and implementing training to be particularly popular amongst educators, instructional designers and training developers. ${ }^{16,17}$ This is because the clearly defined stages help organize teaching content and aid the implementation of teaching tools. However, ADDIE is an instructional design methodology that is not specific to e-learning. This is where Overbaugh's ${ }^{18}$ guidelines for development of computer-based instruction can prove particularly useful, as they address more e-specific issues that ADDIE may miss.

In the ADDIE model, the development of instructional materials usually starts by analyzing the requirements of the resource. ${ }^{16,17}$ Developers of e-learning resources need to understand the People the resource is targeting, what they need to know, what their level of pre-existing knowledge and skills are, their preferred way of learning, what the learning outcomes of the resource will be and how the resource will be delivered. ${ }^{19}$ A useful framework which can be used at this stage is the PACT (People; Activities; Contexts and Technologies). ${ }^{20}$ This framework aids the development of clearly defined learning objectives that reflect what the students should be able to do after completing the resource; the conditions under which they need to perform them and the acceptable standard, ${ }^{16,21}$ before relevant learning activities and assessments are designed. ${ }^{22}$ Learning activities are defined by Beetham ${ }^{23}$ as "a specific interaction of learners(s) with others using specific tools and resources, oriented towards a specific outcome" (p. 28) and are considered to be of primary importance with supporting materials taking a secondary place. ${ }^{23,24}$ Context refers to the physical and social environments for the learning activities as well as the support available and the learner's personal circumstances. Finally, technologies need to be considered with the internet clearly having a central role in providing information and ways for e-learners to interact.

In the design phase of the ADDIE model, a systematic approach should be taken by considering lesson planning, instructional methods, learning objectives, learning activities, content, use of multimedia and the assessment methods to be used. ${ }^{17}$ Resources should be designed with learning theories in mind, viewing learning as a behavior, as a construction of knowledge and as a social practice ${ }^{25}$ with cognitive aspects playing a central role, given that the focus on e-learning is usually on individual learners. ${ }^{19}$

In the development phase, instructional materials and proposed learning content are then further developed and assembled and additional details such as the font to be used, colour and use of graphics are considered. ${ }^{16,17}$ If using illustrations or pictures obtained off the internet it is important that the correct permissions have been obtained or to those available under a creative commons 
license have been used. The resource then needs to be tested and amended in response to the feedback.

Useful to consider during the development phase of the ADDIE model are Overbaugh's ${ }^{18}$ guidelines for the development of computer-based learning, which are based on Gagné's ${ }^{26}$ nine events of instruction framework. Overbaugh grouped the nine events into three domains and added a fourth domain for issues unique to computer-based teaching. The first domain in Overbaugh's ${ }^{18}$ guidelines for the development of computer-based learning is known as instructional set and aims to help the learner to engage with the information that is going to be presented. This domain draws on the first three of Gagné's nine events of instruction and includes gaining learner attention, informing learners of the learning objectives, and stimulating learner recall. ${ }^{26,27}$ The second of Overbaugh's ${ }^{18}$ domains considers teaching strategies and draws on Gagné's fourth, fifth and ninth events of instruction, that is, presenting the content, providing learner guidance and eliciting performance. ${ }^{26,27}$ This includes ensuring that the way the teaching stimulus is presented that is the text, the colour and the graphics are distinctive, providing learner guidance and considering the use of strategies which will facilitate the retention and transfer of new knowledge. The third domain considers eliciting student performance, providing feedback and assessing performance which are also stages six, seven and eight of Gagné's nine events of instruction $^{18,26,27}$ whereas the fourth domain considers other design issues such as learner control and teaching tools, e.g., to reduce anxiety and direct learner attention. ${ }^{18}$

The development phase in the ADDIE model is followed by implementation. ${ }^{17}$ At this stage, any training required to use the e-learning resource is prepared and checks are made to ensure that it is fully functional before it is shared with the learners. In order to reduce the impact of any problems at this stage, an initial pilot run with a small number of learners is advisable so that any teething issues can be addressed before the resource is made available to the wider intended audience. Evaluation is central to the ADDIE process and should be considered at every stage. ${ }^{17}$ For example, in the early stages, it can help determine if the prototype is fit for purpose. ${ }^{28}$ It is also important to test for both usefulness and usability as these are the main components of effective learning. ${ }^{29}$

Pedagogical theories appropriate to e-learning should also be considered and e-resources for adult learners should be based on the principles of adult learning theory or andragogy. ${ }^{30}$ The overarching assumption is that learners are self-directed and independent in their approach to learning, with a preference for flexibility and autonomy in their learning environment. Of relevance to the development of e-learning resources are Mayer's principles of multimedia instructional design. ${ }^{31,32}$ These principles were developed from learning theory and based on evidence and have been shown to improve students' retention of knowledge ${ }^{33}$ and their ability to apply what they have learnt in new situations. ${ }^{34}$ The way in which the underpinning educational and design principles, including Mayer's multimedia principles ${ }^{32}$ were applied when developing the resource is described in detail.

\section{Putting Theory Into Practice During The Design And Development Of The Resource}

A PACT analysis ${ }^{20}$ was conducted to analyse the requirements of the ADHD e-learning resource. The people that the resource was being developed for are medical students. As undergraduates, they will be at least aged 18 when they start the medical course, and are likely to be both intelligent as well as computer literate. Being of the "net generation" they are likely to have a preference for learning environments that are multimedia rich and to enjoy a selfdirected inquiry approach. ${ }^{35}$ The learning outcomes for the ADHD resource are shown in Box 1. These represent the lower levels of knowledge, comprehension and application in the cognitive domain of Bloom's taxonomy, which is used to consider learning outcomes in terms of their complexity and specificity. ${ }^{36}$

The learning activities in the ADHD resource all relate to the learning objectives in Box 1. Additional materials on ADHD were sourced from books, clinical guidelines, reputable websites, online ADHD teaching resources and YouTube. It was envisaged that the context of ADHD resource was that it would be able to be used anywhere and at any time the student had access to a computer and the internet and would be accessible to people with different operating systems and browsers. The resource takes approximately 15 mins to complete, more if a number of the hyperlinks are used. It is suitable

Box I Learning Outcomes Of The Online ADHD Resource

After completing this resource you should:

- Know the clinical features and DSM-V diagnostic criteria of ADHD in children and adolescents

- Know how ADHD in children and adolescents is assessed

- Know the appropriate evidence-based treatments for ADHD according to a child or young person's age and clinical presentation 
for individual study, for example, as preparation for a teaching session about ADHD but also for individuals wishing to acquire knowledge about ADHD as well as to aid revision of the topic. It is for continuous use but can also be stopped and restarted at any point. It does not require any tuition/demonstration or for a manual to be read before use. The technology used by ADHD resource is Xerte Online Toolkits (XOT), which is a free open source tool developed for educational purposes by the University of Nottingham. ${ }^{37}$ Xerte allows the designer to achieve a high level of interactivity and is also user friendly and suitable for use by non-programmers and those without any specialist IT knowledge or skills. The designer does, however, need to have expertise in relation to the page content and the underlying educational theory behind the lesson design. Once published, the learning resource can be amended either by the author, the learners, or by others as it is a shared resource. XOT is accessed via a web browser (Firefox is recommended) but does need Adobe Flash Player to run.

Using the second stage of the ADDIE model, ${ }^{16,17}$ the resource was then designed to meet the needs of the learners. After the learning outcomes had been determined (see Box 1), the instructional methods and media as well as the strategy for instruction were chosen. Tutorials, examples and page templates available on the Xerte Project website were then examined. ${ }^{37}$ The "flexible" XOT page template was chosen as this allowed for different content on the slides. A colleague had given permission for cartoons he had drawn to be used to illustrate some of the slides. To enhance student learning, a combination of conceptual scaffolding as well as procedural scaffolding was used. ${ }^{38}$ The former helps to focus the students on particular aspects of ADHD (e.g. symptoms/diagnosis, assessment and treatment) whilst the latter helps them use the resource. Thus, in the resource, symbols were used to differentiate tasks which need to be completed ( $\S$ ) from additional informa-

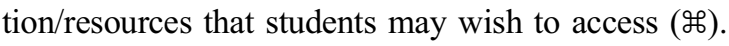

Continuing to follow the ADDIE model, ${ }^{16,17}$ during the development phase of the ADHD resource, Overbaugh's ${ }^{18}$ guidelines were used in conjunction with Meyer's ${ }^{32}$ multimedia principles. Student attention is gained through the title "Naughty Callum", which also indicates the intention to use a case study. Strategies to facilitate maximum sensation are utilized by placing the title in the centre of the slide and using a cartoon picture as a background. By presenting them close together, Mayer's ${ }^{32}$ spatial contiguity principle is used, which helps reduce cognitive load (see Figure 1).

The orientation slide at the start of the ADHD resource states the learning outcomes (see Box 1). Mayer's ${ }^{32}$ pre-training principle is used to ensure that students have the necessary prior knowledge about the names and characteristics of the

\section{'Naughty" Callum}

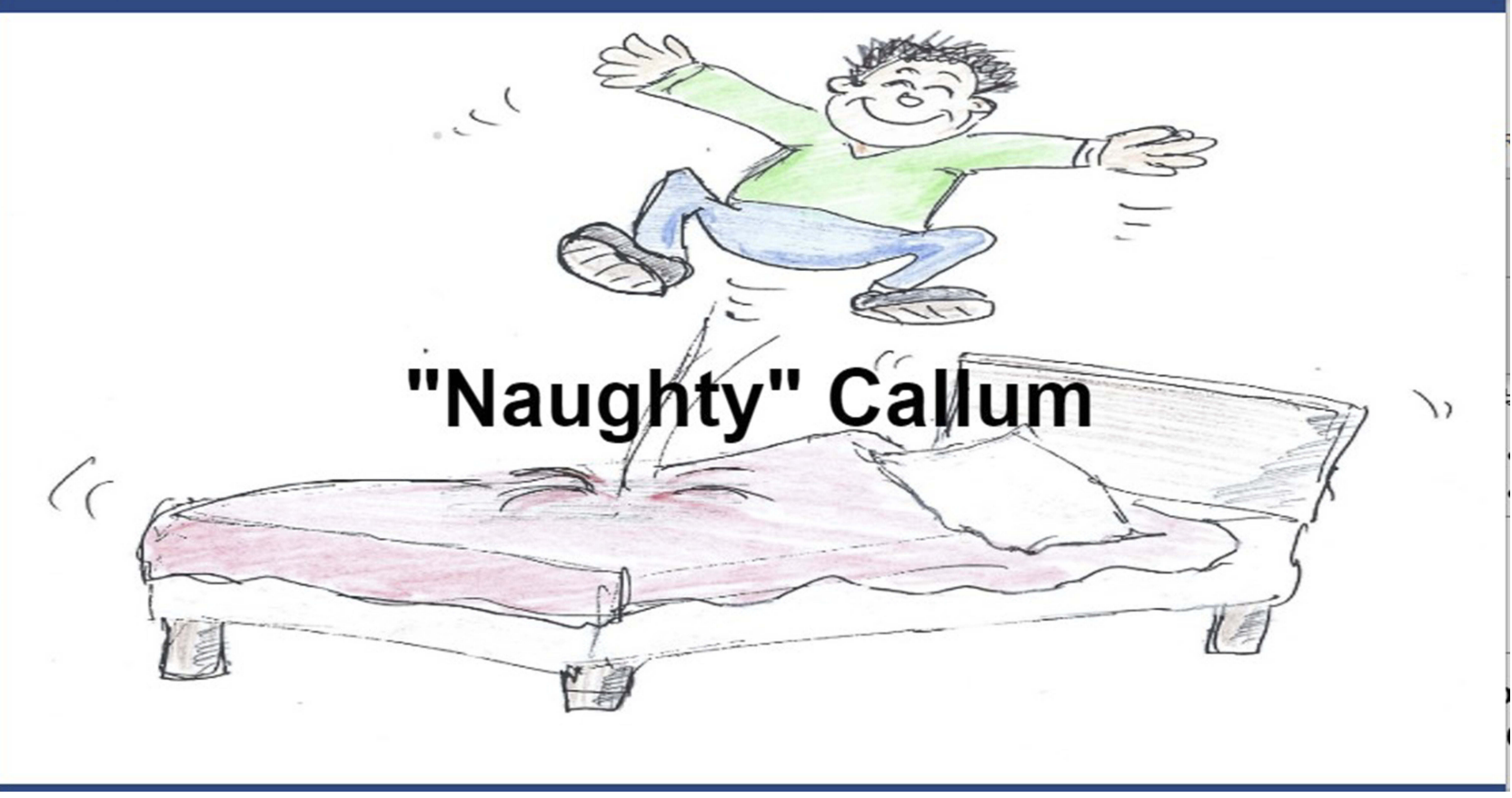

Figure I ADHD resource Slide I showing use of Mayer's spatial contiguity principle. 
main concepts they are to be taught about by offering them hyperlinks to pre-requisite knowledge about ADHD. The provision of anonymous access to remedial materials is also known to relieve information anxiety, that is the gap between what the student knows and what they think they should know. ${ }^{39}$ An overview slide (see Figure 2 ) is then provided using a case study of a child ("Callum") presenting with symptoms suggestive of ADHD. A Case-Based Learning approach (CBL) is used as this presents the learning in an authentic "story-like" manner and enables learners to remember concepts, events, and processes and to recall information. ${ }^{40}$ Maier and Warren ${ }^{41}$ suggest that the cases selected are either historically important, unusual or, as chosen for the ADHD resource, are representative of the condition. The case study is used as an advance organizer, ${ }^{42}$ introducing the topic of ADHD, providing a structure for student thinking and acting as a bridge between their prior knowledge about ADHD and the new information they are about to learn which will help it to be more easily remembered. Meyer's signaling principle ${ }^{32}$ is used to highlight important words in bold where it is not possible to delete extraneous material. Signaling helps guide the student's attention toward the essential material and reduces the processing of unnecessary information. After the ADHD case study, a hyperlink is then offered to a video clip of a similar case. Using Meyer's ${ }^{32}$ multimedia principle that explanations are better presented in words and pictures than just words, alone a cartoon picture is then used to illustrate the text (see Figure 2).
The first few slides of the ADHD resource stimulate recall of the student's prior knowledge by using pre-questions and supplying missing prerequisites via hyperlinks to additional resources. This acts to bring the students up to the same level, as well as catering for their different needs. Interactive formats, e.g., quiz, drag and drop answers (see Figure 3) or writing free text are used.

The different learning styles of the students are catered for by providing similar information using a variety of media, e.g., diagrams or video links on some of the slides. Cartoon graphics, interactive exercises and links to multimedia resources are used throughout the resource to maintain the student's interest. Learner guidance is offered by returning to the case study at different points throughout the resource and elaborating on Callum's progress. The material covered is then reviewed at the end of the resource as this has the effect of enhancing retention, particularly as it is done prior to the final assessment and also aids transfer to practice ${ }^{43}$ (see Figure 4).

Interactive exercises are provided throughout the resource to elicit performance and provide feedback which is immediate, as this is the most effective, and explanatory, with hyperlinks to remedial information to increase motivation. ${ }^{44}$ Assessments that are designed to measure student performance against the learning outcomes occur throughout the ADHD resource. Students are provided with a pre-test before the main learning section, as well as interactive learning activities and self-test items throughout. A final quiz at the

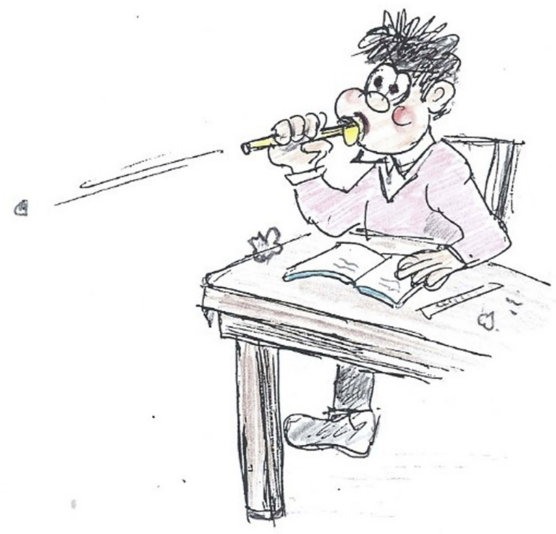

Callum, aged 7 years, has been brought to see his GP. Since he started school, teachers have fedback to his parents that he is difficult to manage. He is often told off for not sitting still and wandering around the classroom. He frequently talks when he is meant to be quiet and disrupts other children. He can't take his turn and often shouts out in class. He can't pay attention for any longer than a few minutes and often loses things he needs in class. When he was younger, his parents and teachers put his behavior down to immaturity and hoped he would grow out of it. Now he is in the junior school, the academic demands have increased and both are concerned.

If you would like to learn more about parenting children like Callum:

Ho watch this short ( $4 \mathrm{~min} 51$ secs) video clip before continuing,

Why Can't You Behave? - My Son Has ADHD (Attention Deficit Hyperactivity Disorder)

https://www.youtube.com/watch?v=nurwo4seVq $\underline{Y}$ 


\section{History Taking}

§ Change the text size at the bottom of the slide to 'small' then click and drag the symptoms into the one of the boxes depending on whether or not you think it is a symptom of inattention, hyperactivity or impulsivity. If you

click on the "check answers" button, a green tick will appear next to the ones you got right, so try again with the ones you didn't. Remember to change the text size back before you move on!

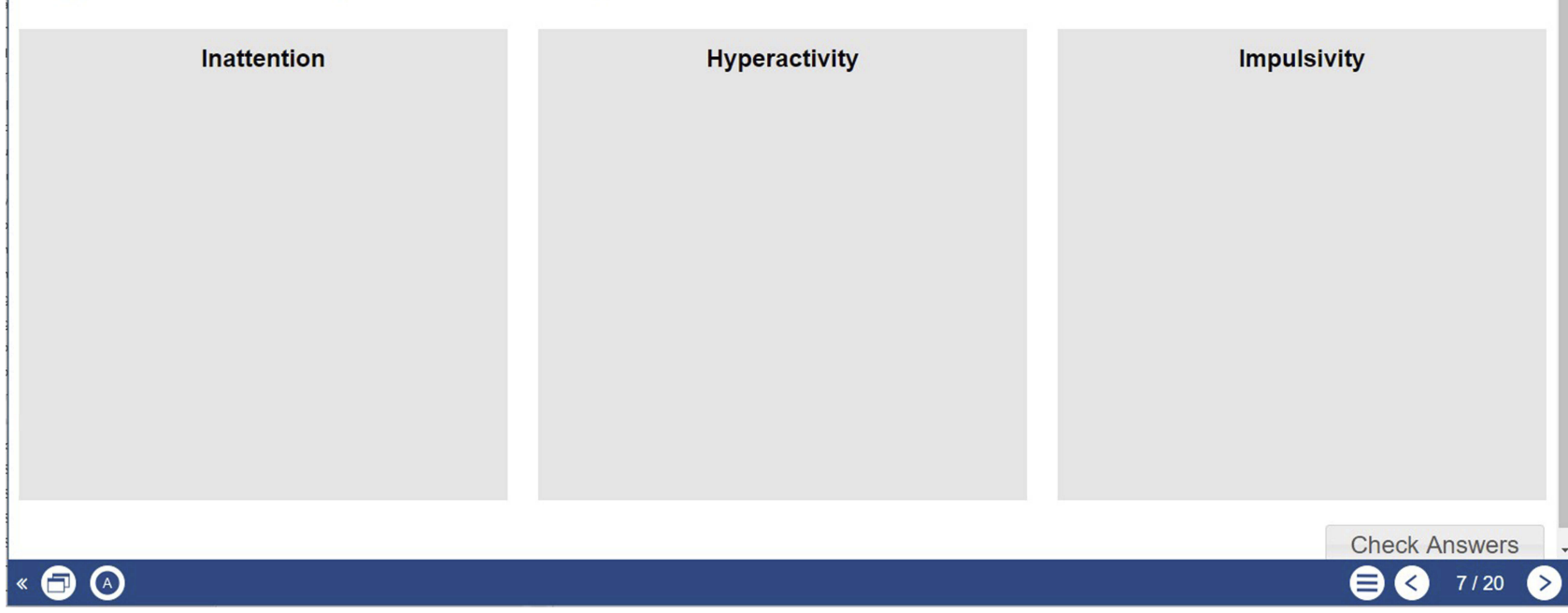

Figure 3 ADHD resource Slide 7 showing use of Interactive formats to stimulate student recall of prior knowledge.

\section{'Naughty" Callum}

\section{Recap time}

Lets now review what you have learnt before you

formally check your knowledge by taking the final quiz on the next slide!.

We have looked at the topic of ADHD from three main perspectives:

\section{Symptoms}

\section{Assessment}

Treatment

H If you click on each heading overleaf- you will find a summary of the information you have already covered.

$\S$ When you are ready, move on to the next slide to take the final quiz!
- Symptoms: Inattention

Fails to give close attention to details or makes careless mistakes.

Has difficulty sustaining attention.

- Symptoms: Hyperactivity

- Symptoms: Impulsivity

- Assessment: Essential for Assessment

- Assessment: Desireable/Might be helpful

Assessment: Unnecessary

Treatment: Treatment for pre-schoolers

Treatment: Treatment for School-age children and Young People

Figure 4 ADHD resource Slide 18 showing review of learning materials to enhance retention.

end of the resource assesses performance and whether the learning outcomes have been met. This consists of ten questions. The first seven questions test the student's memory of what they have learnt (i.e. their recall) and the final three questions test their understanding (i.e. whether they can apply their new knowledge to a different situation). A hyperlink is then given to a humorous video on ADHD.

Throughout the resource, Meyer's personalization principle $^{32}$ is adopted, where a conversational rather than a formal style is used to present the material as this is 
thought to create a sense of social partnership and result in students trying harder to understand. Other principles of multimedia instructional design ${ }^{32}$ were also considered during the development phase of the ADHD resource. For example, Meyer's segmenting principle ${ }^{32}$ that offers learner-paced segments in a logical and organized structure, allowing students to proceed when they are ready, thus reducing the risk of cognitive overload and Mayer's coherence principle ${ }^{32}$ keeping the content of the ADHD resource simple whilst still being meaningful, relevant and interesting, and avoiding the use of unnecessary words, pictures or sounds.

Keller's ${ }^{45}$ ARCS (Attention, Relevance, Confidence, Satisfaction) model to motivate students to learn was also considered during the development phase of the resource. The students' Attention is captured by the use of the case study and illustrative cartoons. The Relevance of the resource is made clear as students are informed at the beginning that "This is a teaching resource on ADHD for medical students". Student Confidence is raised by informing them of the session outcome and student Satisfaction is increased by providing opportunities for self-testing with feedback, enabling students to check their progress.

Using the ADDIE model, during the implementation phase of the e-learning resource, it was important to ensure that the resource that had been designed and developed was actually functional. A number of limitations were encountered with XOT. For example, although advised it would run on Firefox, this was not the case, and another browser (Chrome) had to be installed. Using Chrome, XOT was still unstable, and kept losing connection, having to be frequently restarted with the loss of any unsaved work. Text size had to be the same on all slides which led to problems with "drag and drop" tasks. The background colour is published as, and reverts back, to blue. The ADHD resource is however still accessible to those with visual impairment or colour blindness i.e. difficulty distinguishing between certain colours, as users can alter the text size or background colour themselves.

The ADHD resource needed to be "published" either as Flash or Html to create the necessary hyperlink for it to become operational. The former was chosen, which unfortunately does mean that it cannot be run on a tablet or smartphone as both lead to major changes in the formatting, e.g., loss of bullet points, and bold type, and changes in background colour and slide layout which is clearly a limitation.
The final phase of the ADDIE model is evaluation although in practice, this should occur throughout the development of a learning resource, and not just at the end. With this in mind, the ADHD e-learning resource was evaluated at a number of stages. For example, informal feedback on the format and content was initially sought from an academic child and adolescent psychiatry colleague who had a special interest in ADHD. A brief 12-item "usability" questionnaire was then developed taking one item from each of the areas in Zaharias and Poylymenakou's ${ }^{46}$ 64-item usability questionnaire for e-learning applications. These areas are: navigation, learnability, accessibility, consistency, visual design, interactivity, content and resources, media use, learning strategies design, instructional feedback and assessment and learner guidance and support. Although this approach would be inadequate for a research study, given that this was a smallscale evaluation and not research, it was considered to represent a compromise and could be replicated by others wishing to develop similar online resources for use within their own institutions.

In the first pilot of the resource, ten medical students were offered teaching on ADHD using the resource whilst attending a teaching day on CAP. They were then asked to complete the 12-item "usability" questionnaire. Even though the sample size was small, this was considered sufficient as it has been found that $95 \%$ of usability problems can be discovered in a sample of just five to six people. ${ }^{47}$ Further revisions to the ADHD resource were made in accordance with the students' feedback at this stage. For example, a new instruction was written for users on how to change the font size on a drag and drop exercise to facilitate completion of the exercise and then how to change it back before continuing (as font size has to be the same throughout the resource when using XOT), some information was re-presented as bullet points rather than a paragraph of text and additional information was given in the quiz section about why the answers given were correct/incorrect.

The ADHD resource is designed to collect ongoing user feedback via a SurveyMonkey link on the last XOT slide. This comprises of 5 questions from the 12 questions in the original usability questionnaire asking users to indicate their agreement with a number of statements relating to the resource, one question asking if students would recommend the resource to other medical students and an additional free text question asking for suggestions on how to improve the resource (see Figure 5).

In the second pilot, medical students were given a link to the ADHD e-learning resource and asked to look at it prior to 


\section{Feedback Questionnaire}

(Rate each question from $1=$ strongly disagree, to $7=$ strongly agree)

1. The resource covers the subject in sufficient breadth and depth to meet the learning objectives?

2. The resource offers tools e.g. hyperlinks to additional sources of information that support learning?

3. The final quiz adequately measures accomplishment of the learning objectives?

4. Feedback given at any specific time is tailored to the content being studied or task being completed by the learner?

5. Media (text, cartoon pictures, videos etc) included have a strong connection to the objectives and design of the resource?

6. Would you recommend this online ADHD revision to another medical student?

7. Do you have any suggestions that would improve this resource? (free text)

Figure 5 Survey Monkey Feedback Questionnaire At End Of ADHD E-Learning Resource.

attending a small group teaching session on ADHD. Fifteen students also completed the SurveyMonkey feedback questionnaire at the end of the resource. As can be seen in Figure 6 , for all 6 questions, at least $75 \%$ of the students agreed or strongly agreed with the statements related to the ADHD resource. Notably, of the 15 students who completed the feedback, 14 students indicated that they agreed or strongly agreed that the resource covers the subject (ADHD) in sufficient breadth and depth to meet the learning objectives. $87 \%$ indicated that they would be likely to recommend the online resource to another medical student. Free text comments made by students were positive, also indicating areas that could benefit from further development. Some useful comments on how the resource could be further improved were also offered, e.g., offering additional explanation when an incorrect answer was selected.

\section{Conclusion And Future Directions}

This paper describes the design and development of an e-learning resource for teaching ADHD to undergraduate medical students and demonstrates how educational theory, instructional models and principles can benefit the development of e-learning resources. ${ }^{16-18}$ Using well-established theories and models aided in the organization of content and in designing a learner-centered resource. Moreover, preliminary evaluation revealed that students were satisfied with the resource and felt it helped them acquire knowledge prior to the teaching session. With this in mind, the resource developed may be suitable for use in a flipped classroom approach to teaching ADHD knowledge to medical students. The flipped classroom approach to education is being increasingly considered to be a useful way to deliver essential content to students ${ }^{48}$ Students are provided with material to gain a baseline level of understanding prior to attending a teaching session. This facilitates deeper understanding of concepts and allows in-class teaching time for addressing questions and concerns. ${ }^{49}$ This method is gaining momentum in undergraduate teaching as it relieves classroom time of purely didactic teaching, and allows for the information gained prior to attending the teaching session to be applied (e.g. in a role play clinical scenario). ${ }^{50}$ This moves students away from passive learning towards more active learning 


\section{Student Questionnaire Feedback ( $=15)$}

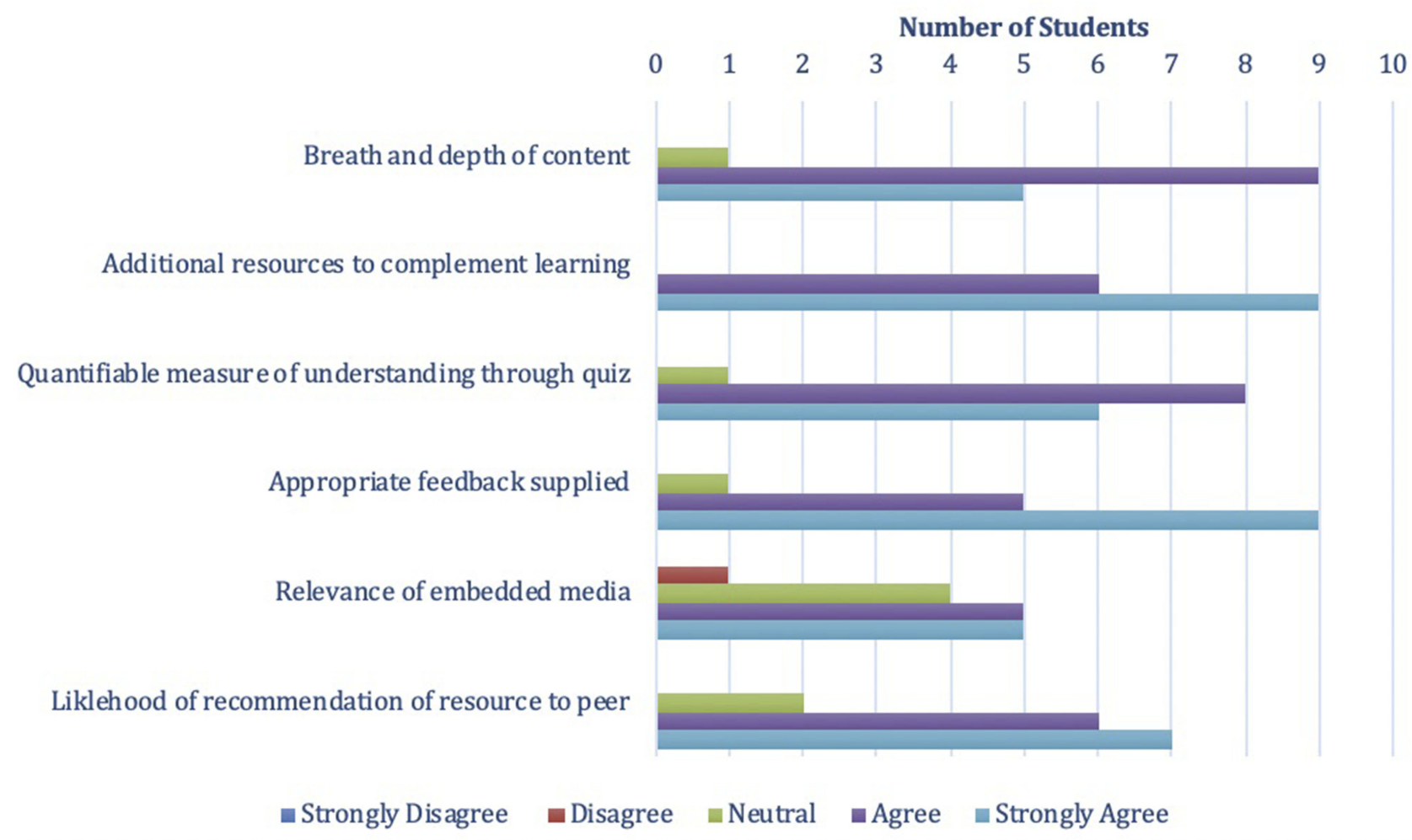

Figure 6 ADHD online resource: Results of the feedback questionnaire.

methods, which have been shown to increase the performance of students as well as giving them autonomy over their own learning. ${ }^{51}$ Materials used prior to attendance at flipped classroom sessions can take a number of forms but increasingly, e-learning resources are being used. ${ }^{35}$ Further evaluation of use of the ADHD resource in that context would now be helpful.

The resource could also provide pre-requisite information on ADHD prior to a clinical skills session for example, where students practice interviewing a parent concerned that their child might have ADHD. In addition, it could act as a revision aid as the interactive sessions can give real-time feedback, through quizzes and end of topic tests with use of active recall. Given the shortage of available teaching hours for undergraduate medical students in CAP, the development of similar e-learning resources may also offer a way to increase time teaching CAP clinical skills related to other disorders whilst providing students with access to self-directed teaching resources to increase their associated knowledge. For those who may consider developing such resources, this paper demonstrates the value of using well-established educational theories and design principles to guide the process.

It is important to note that the evaluation presented in this paper forms part of routine teaching evaluation and cannot be regarded as evaluation research. At present we can only reflect upon some elements of Kirkpatrick's ${ }^{52}$ lower level of evaluation, but this could be expanded upon by considering students' perceptions of their engagement and their interaction with content. In addition, further evaluation could expand to examine learning, changes in behavior and longterm impact through longitudinal studies. This will provide a more robust and comprehensive evaluation of the educational value and the impact of this teaching intervention on knowledge and skill acquisition.

\section{Ethics Approval And Informed Consent}

Ethical approval was not required as the evaluation of the online ADHD resource was an audit and formed part of the resource development and not a formal research study. No personal data were collected. 


\section{Acknowledgement}

Thank you to Richard Barratt for drawing the cartoons in the ADHD e-learning resource and giving his permission for them to be used.

\section{Disclosure}

The authors report no conflicts of interest regarding this work.

\section{References}

1. Kopelman P. The future of UK medical education curriculum - what type of medical graduates do we need? Future Hosp J. 2014;1(1):4146. doi:10.7861/futurehosp.14.011

2. Velthuis F, Varpio L, Helmich E, Dekker H, Jaarsma A. Navigating the complexities of undergraduate medical curriculum change: change leaders' perspectives. Acad Med. 2018;93(10):1503-1510. doi:10.1097/ ACM.0000000000002165

3. Gill P, Kitney L, Kozan D, Lewis M. Online learning in paediatrics: a student-led web-based learning modality. Clin Teach. 2010;7(1):5357. doi:10.1111/tct.2010.7.issue-1

4. McGready J, Brookmeyer R. Evaluation of student outcomes in online vs. campus biostatistics education in a graduate school of public health. Prev Med. 2013;56:142-144. doi:10.1016/j.ypmed.2012.11.020

5. May L, Acquaviva K, Dorfman A, Posey L. Medical student perceptions of self-paced, web-based electives: a descriptive study. $\mathrm{Am} \mathrm{J}$ Distance Educ. 2009;23:212-223. doi:10.1080/08923640903332120

6. Gibbons A, Fairweather P. Computer-based instruction. In: Tobias S, Fletcher J, editors. Training \& Retraining: A Handbook for Business, Industry, Government, and the Military. New York: Macmillan Library Reference; 2000:410-442.

7. Chumley-Jones HS, Dobbie A, Alford CL. Web-based learning: sound educational method or hype? A review of the evaluation literature. Acad Med. 2002;77(10 suppl):S86-S93. doi:10.1097/ 00001888-200210001-00028

8. Warnecke E, Pearson S. Medical students' perceptions of using e-learning to enhance the acquisition of consulting skills. Australas Med J. 2011;4:300-307. doi:10.4066/AMJ.2011.73

9. Ruiz JG, Mintzer MJ, Leipzig RM. The impact of e-learning in medical education. Acad Med. 2008;81(3):207-212. doi:10.1097/ 00001888-200603000-00002

10. Beale EG, Tarwater PM, Lee VH. A retrospective look at replacing face-to-face embryology instruction with online lectures in a human anatomy course. Anat Sci Educ. 2014;7:234-241.

11. Sawyer MG, Giesen F, Walter G. Child psychiatry curricula in undergraduate medical education. $J$ Am Acad Child Adolesc Psychiatry. 2008;47(2):139-147. doi:10.1097/chi.0b013e31815cd9e0

12. Kay J. Child psychiatry and the undergraduate curriculum. $J$ Psychiatr Educ. 1983;7(2):126-137.

13. Worrall-Davies AE. Teaching child and adolescent psychiatry to medical undergraduates. Adv Psychiatr Treat. 1998;4(3):172-176. doi:10.1192/apt.4.3.172

14. Lempp T, Heinzel-Gutenbrunner M, Bachmann C. Child and adolescent psychiatry: which knowledge and skills do primary care physicians need to have? A survey in general practitioners and paediatricians. Eur Child Adolesc Psychiatry. 2016;25(4):443-451. doi:10.1007/s00787-015-0757-6

15. Salmon G, Tombs M. Teaching undergraduate medical students Child and Adolescent Psychiatry (CAP): a Delphi study on curriculum content. BMC Med Educ. 2018;18(1):315. doi:10.1186/s12909-018-1427-4
16. Dick W, Carey L, Carey JO. The Systematic Design of Instruction. 6th ed. Boston: Allyn \& Bacon; 2005.

17. Allen WC. Overview and evolution of the ADDIE training system. Adv Dev Hum Resour. 2006;8(4):430-441. doi:10.1177/1523422306 292942

18. Overbaugh RC. Research-based guidelines for computer-based instruction development. J Res Comput Educ. 1994;27(1):29-47. doi:10.1080/08886504.1994.10782114

19. Sandars J. E-learning. In: Walsh K, editor. Oxford Textbook of Medical Education. Oxford, UK: Oxford; 2013:174-175.

20. Beynon D. Designing Interactive Systems. 2nd ed. Harlow: Pearson; 2010.

21. Molenda M, Pershing JA, Reigeluth CM. Designing instructional systems. In: Craig R, editor. The ASTD Training and Development Handbook: A Guide to Human Resource Development. 4th ed. New York: McGraw-Hill; 1996:266-293.

22. Biggs J. Teaching for Quality Learning at University. Buckingham: Society for Research in Higher Education and Open University Press; 1999.

23. Beetham H. An approach to learning activity design. In: Beetham $\mathrm{H}$, Sharpe R, editors. Rethinking Pedagogy for a Digital Age. Abingdon: Routledge; 2007:26-38.

24. JISC. Effective practice in a digital age: a guide to technology enhanced learning and teaching. 2009. Available from: https:// library.educause.edu/resources/2009/6/effective-practice-in-a-digitalage-a-guide-to-technologyenhanced-learning-and-teaching. Accessed June 11, 2019.

25. Mayes T, de Freitas S. Learning and e-learning: the role of theory. In: Beetham H, Sharpe R, editors. Rethinking Pedagogy for a Digital Age. Abingdon: Routledge; 2007:13-25.

26. Gagné R. The Conditions of Learning. 4th ed. New York, NY: Holt, Rinehart Winst; 1985.

27. Gagné RM, Wager WW, Golas KC, Keller JM, Russell JD. Principles of Instructional Design. 5th ed. Belmont, CA: Thomson Wadworth; 2005.

28. Sandars J, Lafferty N. Twelve tips on usability testing to develop effective e-learning in medical education. Med Teach. 2010;32 (12):956-960. doi:10.3109/0142159X.2010.507709

29. Davis FD. Perceived usefulness, perceived ease of use, and user acceptance of information technology. MIS Q. 1989;13:319-340. doi: $10.2307 / 249008$

30. Knowles M. Self-Directed Learning: A Guide for Learners and Teachers. New York: Assoc. Press; 1975.

31. Association of American Medical Colleges. Effective use of educational technology in medical education. Colloquium on Educational Technology: Recommendations and Guidelines for Medical Educators; 2007. Available from: https://members.aamc.org/eweb/upload/Effective \%20Use\%20of\%20Educational.pdf. Accessed June 11, 2019.

32. Mayer RE. Applying the science of learning: evidence-based principles for the design of multimedia instruction. Am Psychol. 2008;63 (8):760-769. doi:10.1037/0003-066X.63.8.760

33. Issa N, Schuller M, Santacaterina S, et al. Applying multimedia design principles enhances learning in medical education. Med Educ. 2011;45(8):818-826. doi:10.1111/j.1365-2923.2011.03988.x

34. Issa N, Mayer RE, Schuller M, Wang E, Shapiro MB, DaRosa DA. Teaching for understanding in medical classrooms using multimedia design principles. Med Educ. 2013;47(4):388-396. doi:10.1111/ medu.2013.47.issue-4

35. Tapscott D. Growing up Digital: How the Net Generation Is Changing Your World. New York: McGraw-Hill; 2009.

36. Bloom BS, Engelhart MD, Furst EJ, Hill WH, Krathwohl DR. Taxonomy of Educational Objectives: The Classification of Educational Goals. Handbook 1: Cognitive Domain. New York: David McKay Company; 1956. 
37. Xerte Online Toolkits [homepage on the internet]. Nottingham: Nottingham University. Available from: https://www.nottingham.ac. uk/xerte/toolkits.aspx. Accessed May 28, 2019.

38. Hill J, Hannafin M. Teaching and learning in digital environments. The resurgence of resource- based learning. Edu Technol Res Dev. 2001;49(3):37-52. doi:10.1007/BF02504914

39. Grunwald T, Corsbie-Massay C. Guidelines for cognitively efficient multimedia learning tools: educational strategies, cognitive load, and interface design. Acad Med. 2006;81(3):213-223. doi:10.1097/ 00001888-200603000-00003

40. Riesbeck CK, Schank RC. Inside Case-Based Reasoning. Hillsdale, NJ, USA: L. Erlbaum Associates Inc.; 1989.

41. Maier P, Warren A. Integrating Technology in Learning and Teaching: A Practical Guide for Educators. London: Kogan Page; 2000.

42. Ausubel D. The Psychology of Meaningful Verbal Learning. New York: Grune \& Stratton; 1963.

43. Jonassen DH, Hannum WH. Research-based principles for designing computer software. Instructional Technol. 1987;27(12):7-14.

44. Schimmel BJ. Providing meaningful feedback in courseware. In: Jonassen D, editor. Instructional Designs for Microcomputer Software. Hillsdale, NJ: Lawrence Erlbaum; 1988:183-196.
45. Keller JM. Motivational design of instruction. In: Reigeluth CM, editor. Instructional Design Theories and Instruction: An Overview of Their Current Status. Hillsdale, NJ: Lawrence Erlbaum; 1983.

46. Zaharias P, Poylymenakou A. Developing a usability evaluation method for e-learning applications: beyond functional usability. Intl J Hum Comput Int. 2009;25(1):75-98. doi:10.1080/10447310802546716

47. Nielsen J. Usability Engineering. San Francisco: Elsevier; 1994.

48. Mazur A, Brown B, Jacobsen M. Conception d'apprentissage à l'aide de l'instruction en classe inversée [Learning designs using flipped classroom instruction]. Can J Learn Technol Rev Can l'apprentissage la Technol. 2015;41(2):1-26.

49. Tucker B. The flipped classroom: online instruction at home frees class time for learning. Educ Next. 2012;12(1):82-84.

50. Amini R, Laughlin BS, Smith KW, Siwik VP, Adamas-Rappaport WJ, Fantry GT. "Flipped classroom" for academic and career advising: an innovative technique for medical student advising. Adv Med Educ Pract. 2018;9:371. doi:10.2147/AMEP.S162504

51. Freeman S, Eddy SL, McDonough M, et al. Active learning increases student performance in science, engineering, and mathematics. Proc Natl Acad Sci. 2014;111(23):8410-8415. doi:10.1073/pnas.1319030111

52. Kirkpatrick DL, Kirkpatrick JD. Evaluating Training Programs: The Four Levels. 3rd ed. San Francisco, CA: Berrett-Koehler Publishers; 2006.

\section{Publish your work in this journal}

Advances in Medical Education and Practice is an international, peerreviewed, open access journal that aims to present and publish research on Medical Education covering medical, dental, nursing and allied health care professional education. The journal covers undergraduate education, postgraduate training and continuing medical education including emerging trends and innovative models linking education, research, and health care services. The manuscript management system is completely online and includes a very quick and fair peer-review system. Visit http://www.dovepress.com/testimonials.php to read real quotes from published authors. 